This is an electronic reprint of the original article. This reprint may differ from the original in pagination and typographic detail. Author(s): Földes, Tamás; Madarász, Ádám; Révész, Ágnes; Dobi, Zoltán; Varga, Szilárd; Hamza,
Andrea; Nagy, Péter R.; Pihko, Petri; Pápai, Imre

Title: $\quad$ Stereocontrol in Diphenylprolinol Silyl Ether Catalyzed Michael Additions : Steric Shielding or Curtin-Hammett Scenario?

Year: $\quad 2017$

Version:

Please cite the original version:

Földes, T., Madarász, Á., Révész, Á., Dobi, Z., Varga, S., Hamza, A., Nagy, P. R., Pihko, P., \& Pápai, I. (2017). Stereocontrol in Diphenylprolinol Silyl Ether Catalyzed Michael Additions : Steric Shielding or Curtin-Hammett Scenario?. Journal of the American Chemical Society, 139(47), 17052-17063. https://doi.org/10.1021/jacs.7b07097

All material supplied via JYX is protected by copyright and other intellectual property rights, and duplication or sale of all or part of any of the repository collections is not permitted, except that material may be duplicated by you for your research use or educational purposes in electronic or print form. You must obtain permission for any other use. Electronic or print copies may not be offered, whether for sale or otherwise to anyone who is not an authorised user. 


\section{Stereocontrol in Diphenylprolinol Silyl Ether Catalyzed Michael Additions: Steric Shielding or Curtin-Hammett Scenario?}

Tamás Földes, Ádám Madarász, Ágnes Révész, Zoltán Dobi, Szilárd

Varga, Andrea Hamza, Péter R. Nagy, Petri M. Pihko, and Imre Pápai

J. Am. Chem. Soc., Just Accepted Manuscript • DOI: 10.1021/jacs.7b07097 • Publication Date (Web): 01 Nov 2017

Downloaded from http://pubs.acs.org on November 3, 2017

\section{Just Accepted}

"Just Accepted" manuscripts have been peer-reviewed and accepted for publication. They are posted online prior to technical editing, formatting for publication and author proofing. The American Chemical Society provides "Just Accepted" as a free service to the research community to expedite the dissemination of scientific material as soon as possible after acceptance. "Just Accepted" manuscripts appear in full in PDF format accompanied by an HTML abstract. "Just Accepted" manuscripts have been fully peer reviewed, but should not be considered the official version of record. They are accessible to all readers and citable by the Digital Object Identifier (DOI®). "Just Accepted" is an optional service offered to authors. Therefore, the "Just Accepted" Web site may not include all articles that will be published in the journal. After a manuscript is technically edited and formatted, it will be removed from the "Just Accepted" Web site and published as an ASAP article. Note that technical editing may introduce minor changes to the manuscript text and/or graphics which could affect content, and all legal disclaimers and ethical guidelines that apply to the journal pertain. ACS cannot be held responsible for errors or consequences arising from the use of information contained in these "Just Accepted" manuscripts. 


\section{INTRODUCTION}

Diarylprolinol silyl ethers developed independently by Jørgensen and Hayashi represent one of the most successfully applied organocatalyst families in contemporary asymmetric synthesis. ${ }^{1} \quad$ These chiral secondary amines provide several activation modes for aldehydes, and enable a broad range of enantioselective functionalizations as well as various multi-step and domino transformations. ${ }^{2}$ The related catalytic cycles are known to involve classical enamine and iminium ion species as the main intermediates, however, the underlying reaction mechanisms are rather versatile and sometimes more complex than foreseen. Diarylprolinol silyl ether catalyzed Michael additions between aldehydes and nitroalkenes (Scheme 1) have been of particular interest for mechanistic studies, ${ }^{3,4,5}$ which have revealed interesting new insights, but also have led to conflicting views with regard to the stereochemical control. ${ }^{6}$
Scheme 1. Organocatalytic Michael reactions between aldehydes and nitroolefins. ${ }^{\text {a }}$

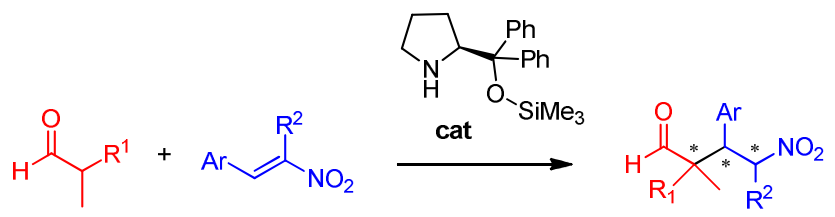

a cat denotes the most frequently used Jørgensen-Hayashi catalyst with the $\mathrm{CPh}_{2} \mathrm{OSiMe}_{3}$ substituent on the pyrrolidine ring.

Mechanistic studies reported by Blackmond, ${ }^{3}$ Seebach, Hayashi and co-workers ${ }^{4}$ pointed to the presence of a stable cyclobutane (CB) intermediate in the catalytic process, which was later shown to be in fast equilibrium with another cyclic species, namely with a dihydrooxazine N-oxide (OO) intermediate (Scheme 2). ${ }^{4 \mathrm{~b}, 5}$ These cyclic species, also referred to as downstream intermediates, are produced in the $\mathrm{C}-\mathrm{C}$ bond formation step of the cycle either via a zwitterionic species, or as computations suggest, directly via spontaneous ring closure to OO. ${ }^{5}$ The mechanistic investigations have also highlighted the 
beneficial role of acid co-catalysts, which accelerate several steps in the cycle including the protonation of cyclic intermediates (or related zwitterions). ${ }^{7}$ This latter process was suggested to be the turnover-determining step of the reaction leading to an iminium intermediate, which then undergoes hydrolysis to furnish the nitroaldehyde product (Scheme 2). ${ }^{8}$ The importance of cyclic OO/CB species is thus clearly recognized, however, their role in the catalytic cycle (e.g. whether they are onor off-cycle species) and particularly in achieving high stereoselectivity has been debated.

Scheme 2. Two key steps of the catalytic cycle in the Michael addition of propanal to $\beta$-nitrostyrene. ${ }^{a}$

\section{C-C bond formation}
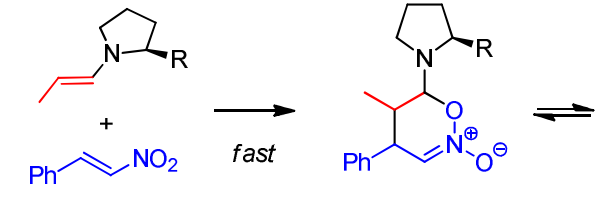

০o

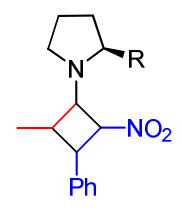

$\mathrm{CB}$ cyclic intermediates

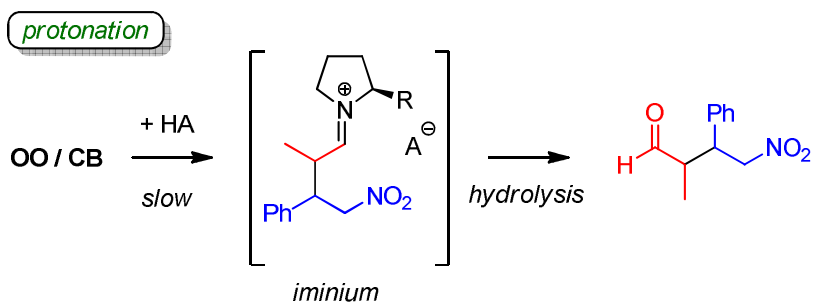

${ }^{\mathrm{a}} \mathrm{R}$ denotes the bulky $\mathrm{CPh}_{2} \mathrm{OSiMe}_{3}$ pyrrolidine substituent.

The stereocontrol in reactions promoted by JørgensenHayashi catalysts is commonly interpreted via a simple steric shielding model that emphasizes the selective formation of sterically less hindered enamine (or iminium) isomers and facial differentiation upon the approach of the reacting partners. This model has been applied to the present Michael reaction as well, and considering the Seebach-Golinski topological rules, ${ }^{9}$ the observed stereoselectivity could be readily rationalized. The steric shielding model implies that the stereoselectivity is under kinetic control and it is governed by the free energy difference of stereogenic $\mathrm{C}-\mathrm{C}$ bond formation transition states as illustrated in Figure 1a. The model implicitly assumes that the transition states of the subsequent steps lie much lower in free energy than that of the $\mathrm{C}-\mathrm{C}$ bond formation and they do not influence the stereoselectivity and the reaction rate.

In light of the mechanistic developments mentioned above, an alternative stereoselectivity model has been introduced by Blackmond and co-workers. ${ }^{3 \mathrm{~b}}$ In their view, the stereoisomeric downstream intermediates can rapidly interconvert, and the product ratio is actually dictated by the relative stability and reactivity of these intermediates. According to this model, referred to as Curtin-Hammett scenario of stereocontrol, the stereoselectivity is related to the free energy difference of transition states corresponding to the rate-determining step subsequent to $\mathrm{C}-\mathrm{C}$ bond formation. Thus, any stereochemical bias imposed by the first step would then be inconsequential since the selection for the major and minor enantiomers would take place at the second step (see Figure $1 \mathrm{~b}$ ). The postponed stereocontrol in Michael reactions catalyzed by Jørgensen-Hayashi catalyst found support from mass spectroscopic studies by Pfaltz and Wennemers. ${ }^{10}$ In this study, the forward and back reactions gave rise to different enantioselectivities when the reactions were promoted by the diarylprolinol silyl ether catalyst, and the authors concluded that this result is not consistent with a stereoselectivity-determining $\mathrm{C}-\mathrm{C}$ bond formation step.

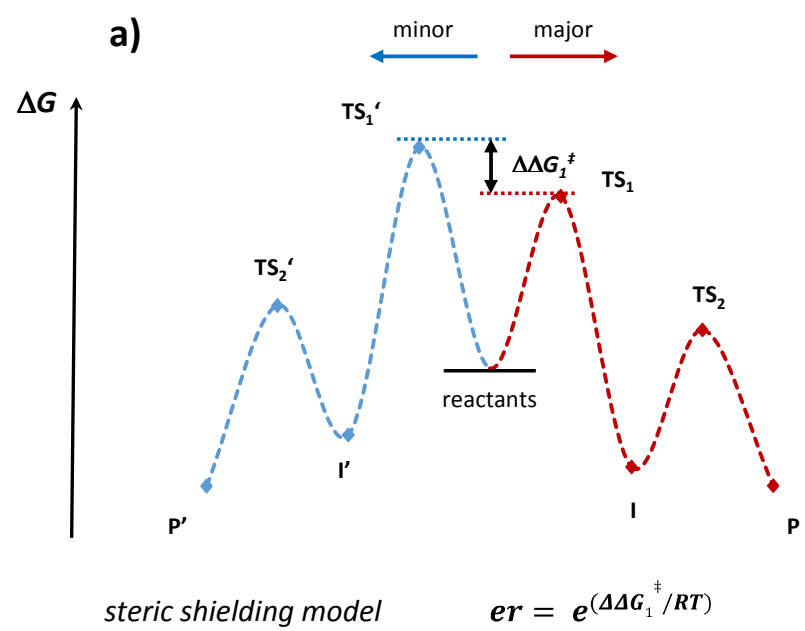

b)

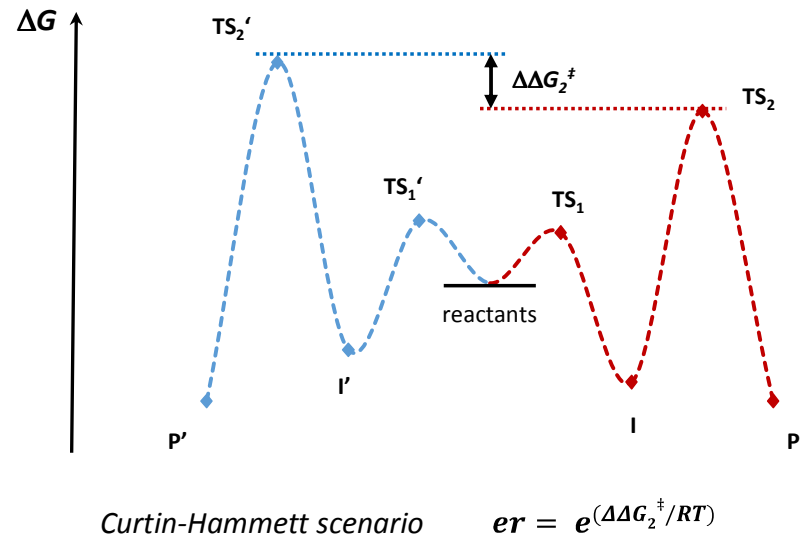

Figure 1: Stereoselectivity models proposed in the literature as illustrated in terms of qualitative free energy diagrams. The catalytic cycle is represented by two elementary steps for simplicity. $\mathbf{T S}_{\mathbf{1}}$ and $\mathbf{T S}_{\mathbf{2}}$ refer to transition states of two key steps in the reaction ( $\mathrm{C}-\mathrm{C}$ bond formation and protonation), but note that these steps formally include other mechanistically relevant elementary steps as well. Further notations: $\mathbf{I}=\mathrm{OO} / \mathrm{CB}$ intermediates, $\mathbf{P}=$ product. Corresponding states on the pathway leading to the minor product stereoisomer are labeled with prime. 
These two stereoselectivity models are in sharp contrast regarding the underlying concepts, and they assume very different approaches in catalyst design. While the steric shielding model provides a relatively simple way of predicting the enantioselectivity of the reaction, the Curtin-Hammett scenario proposed by Blackmond implies that the selectivity should be inferred from the relative thermodynamic stabilities and reactivities of the intermediates. Unfortunately, the minor diastereomeric intermediate species have thus far escaped experimental detection, perhaps due to their low relative stabilities and, hence, low concentrations.

Computational studies, however, are not limited by the stabilities of the observable intermediates or products, and can provide important contributions in elucidating the mechanism of organocatalytic transformations. ${ }^{11}$ Reactions catalyzed by diarylprolinol silyl ethers have been the subject of several computational investigations, ${ }^{12}$ which shed light on mechanistic details and brought insight into the origin of stereoselectivity. ${ }^{13}$ The stereocontrol in the Michael reaction between propanal (1) and $\beta$-nitrostyrene (2) (Scheme 3) has been examined computationally by two groups, ${ }^{14,15}$ both focusing only on the stereogenic $\mathrm{C}-\mathrm{C}$ bond formation step. The energy barriers associated with the most favored transition states leading to the four stereoisomeric products were found to be in perfect agreement with the observed stereoselectivities, a result that is at least consistent with the steric shielding model.

Scheme 3: Four product isomers formed in the reaction between propanal and $\beta$-nitrostyrene.
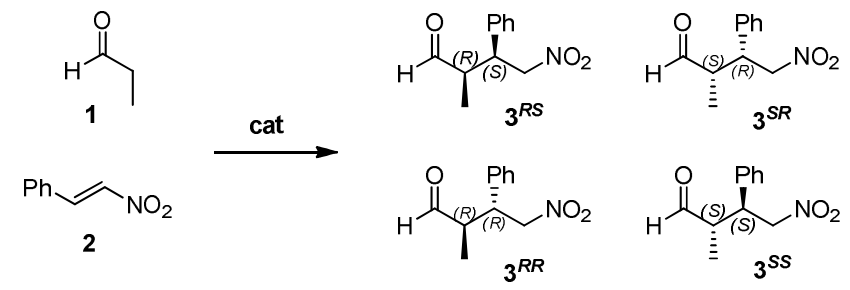

In our present work, we re-examine the $\mathrm{C}-\mathrm{C}$ bond formation transition states for the same reaction using a more advanced computational approach that a) accounts for dispersion interactions known to be essential to capture stereoselectivity effects, b) takes into account various corrections to electronic energies (thermal and entropic contributions as well as solvent effects), and c) considers and scrutinizes the increased complexity of conformational space in the molecular model. All these methodological aspects turn out to be important in predicting reliable relative free energies for competing transition states. ${ }^{16}$ Furthermore, we explore the variety of diastereomeric cyclic intermediates formed upon C-C bond formation pathways and analyze the kinetics of their interconversion as well. The effect of an acid cocatalyst ( $p$-nitrophenol) on the energetics of these processes is explored. This extended molecular model allowed us to examine the protonation step of the catalytic cycle, so the controversial issue concerning the proposed stereoselectivity models could be addressed as well. Our results point to a kinetic scenario, where the stereoselectivity-determining step is consistent with the steric shielding model, but the turnover-limiting step is later in the catalytic cycle, after the formation of the stable downstream intermediates. The computed free energy profile accounts well not only for the observed enantioselectivity, but also for the seemingly anomalous results of the mass spectrometric back reaction screening experiments.

Computational details. The conformational space of molecular models examined in our study is rather complex (see below), so the sound identification of the most relevant conformers required special attention. Some of the conformational possibilities (for instance, the $E / Z$ and $s$ cis/s-trans isomerism of enamine and the facial approach of the electrophile) could be explored systematically, however, other conformational aspects (the puckering mode of the pyrrolidine ring, the orientation of the bulky substituent, and the position of the acid co-catalyst) turned out to be important as well. ${ }^{17}$ Our conformational analysis thus involved an initial Monte Carlo sampling using a parametrized force field, namely a slightly modified version of the OPLS_2005 force field. The modification concerns the partial atomic charges used to estimate the energy contribution of Coulomb interactions. These parameters were obtained from density functional theory (DFT) calculations as electrostatic potential (ESP) derived atomic charges. The conformational analysis was carried out using the MacroModel software. ${ }^{18}$ The Monte Carlo screening was applied not only for reaction intermediates, but also for transition states. Several, at least a dozen, structurally distinct conformers were selected for geometry optimizations, which were carried out via density functional theory (DFT) calculations.

The DFT calculations were performed by using the dispersion-corrected, range-separated hybrid $\omega$ B97X-D exchange-correlation functional ${ }^{19}$ along with the $6-311 \mathrm{G}(\mathrm{d}, \mathrm{p})$ polarized triple- $\zeta$ basis $\operatorname{set}^{20}$ as implemented in the Gaussianog package. $^{21}$ For each located structure, we performed vibrational normal mode analysis to verify the nature of the obtained stationary point (energy minimum or transition state), and also to estimate the thermal and entropic contributions. From transition state structures, we followed intrinsic reaction coordinate (IRC) pathways in both forward and reverse directions, using a Hessian-based predictor-corrector algorithm, ${ }^{22}$ and we identified the related intermediates accordingly. Additional single-point energies with the larger 6-311++G(3df,3pd) basis set were obtained for all structures. In all DFT calculations, the ultrafine integration grid was employed to warrant the accuracy of numerical integration.

The thermal and entropic contributions were estimated within the ideal gas - rigid rotor - harmonic oscillator approximation for $T=298.15 \mathrm{~K}$ and $c=1 \mathrm{~mol} / \mathrm{dm}^{3}$ conditions. The solvent effects were taken into account as well by computing the solvation free energies (at the $\omega \mathrm{B}_{97 \mathrm{X}-\mathrm{D} / 6-}$ $311 G(d, p)$ level $)$ via the integral equation formalism variant of the polarizable continuum model (IEFPCM). ${ }^{23}$ The atomic radii and non-electrostatic terms in the IEFPCM calculations were those of the SMD solvation model. ${ }^{24}$ We used 
chloroform and toluene in PCM calculations to model the two most frequently employed solvent media in experiments.

The energy values reported throughout the paper refer to solution phase Gibbs free energies (for chloroform), ${ }^{25}$ which were obtained from $\omega \mathrm{B} 97 \mathrm{X}-\mathrm{D} / 6-311++\mathrm{G}(3 \mathrm{df}, 3 \mathrm{pd})$ electronic energies and all additional terms computed at the $\omega \mathrm{B} 97 \mathrm{X}-$ $\mathrm{D} / 6-311 \mathrm{G}(\mathrm{d}, \mathrm{p})$ level. Previous benchmark calculations ${ }^{26}$ indicate that the $\omega \mathrm{B} 97 \mathrm{X}-\mathrm{D}$ functional represents a very promising DFT method yielding reasonably accurate data for general main group thermochemistry, kinetics and noncovalent interactions. To assess the uncertainty of energy predictions for the present reaction, we carried out benchmark calculations for an analogous system, namely for the Michael reaction between morpholine enamine of propanal and $\beta$-nitrostyrene. ${ }^{27}$ In this benchmark study, high-level $a b$ initio relative energies were calculated for the relevant species and transition states utilizing a low-order scaling, local natural orbital (LNO) $\operatorname{CCSD}(\mathrm{T})$ method as implemented in the MRCC program suite. ${ }^{28} \mathrm{LNO}-\mathrm{CCSD}(\mathrm{T})$ energies at the complete basis set (CBS) limit were approached via extrapolation techniques employing the augcc-pVTZ and aug-cc-pVQZ basis sets. ${ }^{29}$ The obtained LNO$\operatorname{CCSD}(\mathrm{T}) / \mathrm{CBS}$ quality electronic energies served us as solid reference to estimate the uncertainty of $\omega \mathrm{B}_{97 \mathrm{X}-\mathrm{D} / 6-}$ $311++G(3 \mathrm{df}, 3 \mathrm{pd})$ predictions. The mean absolute deviation of the $\omega \mathrm{B} 97 \mathrm{X}-\mathrm{D} / 6-311++\mathrm{G}(3 \mathrm{df}, 3 \mathrm{pd})$ results from the LNO$\operatorname{CCSD}(\mathrm{T}) / \mathrm{CBS}$ data is found to be $2.0 \mathrm{kcal} / \mathrm{mol}$ (the maximum absolute deviation is $2.9 \mathrm{kcal} / \mathrm{mol}$ ), which is quite reassuring. Even more importantly, the deviations are found to be systematic, so the relative energies of intermediates and transition states reported in our present work can be regarded as reasonable predictions. ${ }^{30}$ The approximations employed in the calculation of gas-phase entropic contributions and the empirical ingredients of the polarizable continuum solvent model add further uncertainties to the computed relative Gibbs free energies, which should also be taken into account when drawing conclusions.

\section{RESULTS}

Enamine isomers. Enamine species that were formed via fast condensation reactions between catalyst cat and aldehydes have been characterized structurally by several methods including $\mathrm{X}$-ray ${ }^{31}$ and $\mathrm{NMR}^{32}$ studies as well as computations. ${ }^{14,15,33}$ In accordance with previous computational results, the present method predicts the $E$ s-trans form to be the most stable conformer for the propanal-derived enamine (denoted as en), whereas the sterically most hindered Z-s-cis structure is significantly destabilized (see Scheme 4).

The thermodynamically most favored enamine isomer (en $^{\text {E-s-trans }}$ ) displays the same conformations regarding the puckering of the pyrrolidine ring (down conformer) and the orientation of the bulky substituent (sc-exo conformer) as revealed by solution-phase NMR measurements reported by Gschwind (Figure 2). ${ }^{32 \mathrm{~b}}$ These features are apparent in the en ${ }^{\text {-s-cis }}$ conformer as well, however, the $\mathrm{SiMe}_{3}$ group in this structure is tilted away from the enamine unit (rotated by 120 degrees around the C-O bond) for steric reasons. Our analysis indicates that conformational changes with respect to these structural parameters (ring puckering, rotations around $\mathrm{C}-\mathrm{C}$ bond) are kinetically feasible, so we mapped all these conformers at every stage of the reaction (for each intermediate and transition state). ${ }^{34}$

\section{Scheme 4: Various isomers of enamine en.}

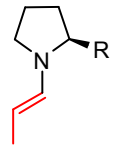

E-s-trans

$(0.0)$

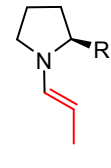

E-s-cis

(2.0)

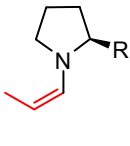

Z-s-trans

(2.5)

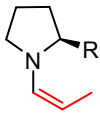

-s-cis

(6.4)
${ }^{\mathrm{a}}$ Relative stabilities are given in $\mathrm{kcal} / \mathrm{mol}$ with respect to the most stable form.

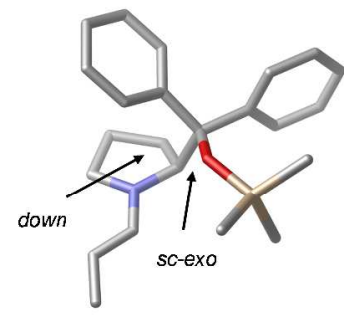

en E-s-trans $(0.0)$

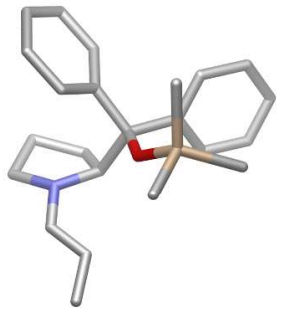

en ${ }^{E-s-c i s}(2.0)$
Figure 2: Structures of two most stable en conformers relevant in the present reaction. Relative stabilities are given in $\mathrm{kcal} / \mathrm{mol}$. All $\mathrm{H}$ atoms are omitted for clarity.

The formation of the propanal-enamine (en) is predicted to be nearly thermoneutral $(\Delta G=-0.5 \mathrm{kcal} / \mathrm{mol}$ for cat $+\mathbf{1} \rightarrow$ en $+\mathrm{H}_{2} \mathrm{O}$, considering the most stable forms of reaction components), ${ }^{35}$ which is consistent with the equilibria observed experimentally for related stoichiometric reactions. ${ }^{4 \mathrm{a}}$

C-C bond formation step. Our extensive conformational analysis carried out for the $\mathrm{C}-\mathrm{C}$ bond formation transition states leading to the four nitroaldehyde product stereoisomers uncovered a set of close-lying conformers on each stereoisomeric pathway, of which the most stable structures are depicted in Figure 3. ${ }^{36}$ All these structures portray that $\beta$-nitrostyrene preferentially approaches from the unhindered face of $E$ enamine isomers (either E-s-trans or E-s-cis) with the gauche arrangement of the two double bonds, and having the $\mathrm{NO}_{2}$ group close to the pyrrolidine ring. ${ }^{37}$ These structural characteristics basically reflect the main ingredients of the common steric shielding model including the Seebach-Golinski topological rule.

Comparison of these transition state conformers with the corresponding enamine structures indicates that the pyrrolidine ring and the bulky substituent of the enamine intermediate can undergo conformational changes upon the approach of $\beta$-nitrostyrene. In transition state $\mathbf{T S}_{\mathbf{C C}}{ }^{R S}$, which leads to the formation of the major stereoisomeric Michael product $\left(3^{R S}\right)$, the pyrrolidine ring puckering and the orientation of the $\mathrm{SiMe}_{3}$ group are altered with respect to en ${ }^{\text {E-s-trans }}$. Even the entire bulky substituent 
may adopt a different conformation as exemplified by $\mathbf{T S}_{\mathrm{Cc}}{ }^{\text {ss }}$ (sc-endo conformation of the bulky group). These aspects of conformational complexity were disregarded in previous computational studies, ${ }^{5,14,15}$ and indeed we find that the transition states identified in our present work do not fully match with those reported earlier. For example, the $\mathbf{T S}_{\mathrm{CC}}{ }^{R S}$ conformation discussed in our previous paper ${ }^{5}$ is fully consistent with en ${ }^{\text {E-s-trans }}$ (down pyrrolidine conformation and same orientation of the bulky substituent), however, it is predicted to be 2.4 $\mathrm{kcal} / \mathrm{mol}$ higher in free energy than that shown in Figure 3. Furthermore, our comparative analysis with the structures published by Sunoj ${ }^{14}$ and Gan $^{15}$ reveals deviations not only in the conformations of the pyrrolidine ring and the bulky side-group, but in some cases, also in the $E / Z$ isomerism of the enamine (in $\mathrm{TS}_{\mathrm{CC}}{ }^{S S}$ ), and in the position of the $\mathrm{NO}_{2}$ group of the approaching $\beta$-nitrostyrene (in $\mathbf{T S}_{\mathrm{CC}}{ }^{R R}$ ).$^{8}$ These additional inconsistencies most likely arise from the low level of DFT applied in earlier studies, but the omission of thermal, entropic and solvent effects can have a notable influence on the relative stabilities as well. ${ }^{39}$
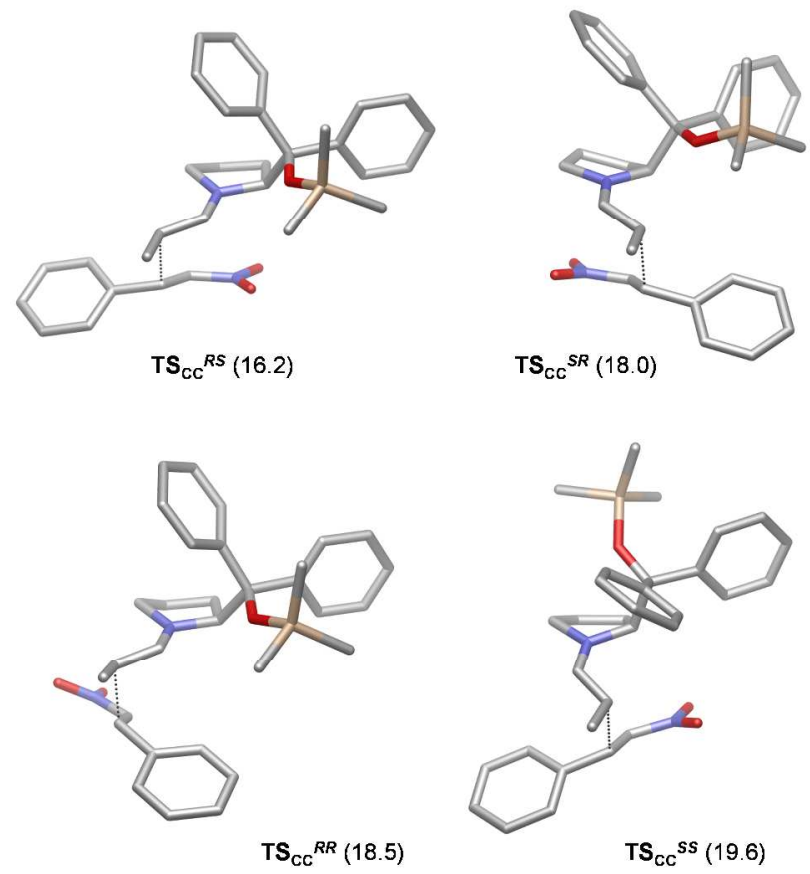

Figure 3: The most favored $\mathrm{C}-\mathrm{C}$ bond formation transition states identified along the four pathways in the reaction between $\mathbf{1}$ and 2. Relative stabilities are given in $\mathrm{kcal} / \mathrm{mol}$ with respect to the reactant state $(\mathbf{1}+\mathbf{2}+\mathbf{c a t})$. The developing $\mathrm{C}-\mathrm{C}$ bond is illustrated by dotted line.

In order to quantify the discrepancies of these predictions in terms of the energetics, we used our present methodology to compute the Gibbs free energies for the previously published transition states as well..$^{40}$ The results shown in Figure 4 indicate that transition states identified in this work are almost all lower in free energy than those reported by Sunoj and Gan. The stabilization obtained by finding more favorable conformations with respect to parameters mentioned above (and using a more reliable computational approach) ranges between $2-6 \mathrm{kcal} / \mathrm{mol}$, which is rather significant when the aim is to reproduce and rationalize experimentally observed stereoselectivities. ${ }^{41}$

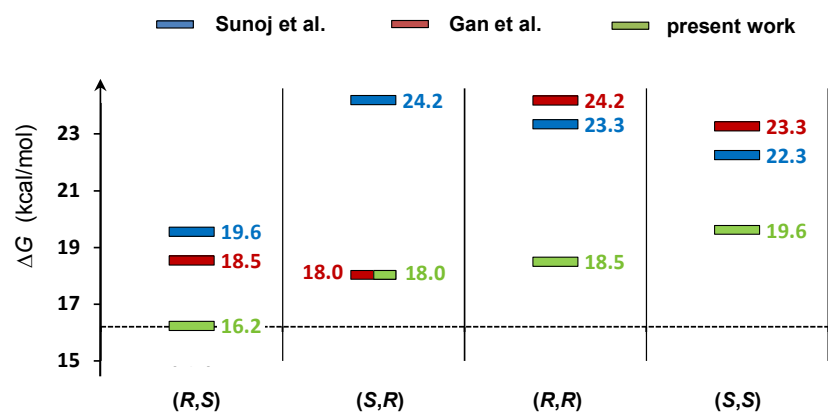

Figure 4: Relative stabilities of transition states identified in the present and previous computational studies. Free energy data are given with respect to the reactant state $(\mathbf{1}+\mathbf{2}+\mathbf{c a t})$

Considering the revised free energy data, the stereoselectivity derived from the free energies of C-C bond formation transition states is still in qualitative agreement with experimental findings, although the free energy differences are far less pronounced than those in previous computations. For instance, the $\Delta \Delta G^{\ddagger}=1.8$ $\mathrm{kcal} / \mathrm{mol}$ obtained for the free energy difference between the $\mathbf{T S}_{\mathrm{CC}}{ }^{R S}$ and $\mathbf{T S}{ }_{\mathrm{CC}}{ }^{S R}$ transition states gives $e e=91 \%$ for the enantiomeric excess, which is in reasonable agreement with experiment $(e e=99 \%) .{ }^{\text {bb }}$

Cyclic intermediates and their interconversion. As demonstrated previously, ${ }^{5}$ the $\mathrm{C}-\mathrm{C}$ bond formation process on the $(R, S)$ pathway leads to spontaneous ring closure and the formation of cyclic $\mathbf{O O}^{R S}$ species, which can easily transform into more stable cyclobutane $\mathbf{C B}^{R S}$ via zwitterion-like transition state. The revised free energy data for these transformations are shown in Scheme 5 along with those obtained for the other three stereoisomeric pathways as well. ${ }^{42}$

On the $(S, R)$ pathway, we find very similar ring closure event leading to $\mathbf{O O}^{S R}$. Related IRC calculations indicate that the formation of the six-membered ring occurs in a single step via an asynchronous concerted mechanism (ring closure lags behind $\mathrm{C}-\mathrm{C}$ bond formation along the reaction coordinate). The $\mathbf{O O}^{S R}$ species can easily transform into $\mathbf{C B}^{S R}$, but the $\mathbf{O O}^{S R}$ intermediate is notably less stable than $\mathbf{O O}^{R S}$ (by $4.2 \mathrm{kcal} / \mathrm{mol}$ ). On the other hand, cyclobutane $\mathbf{C B}^{S R}$ is predicted to be well below the reactant level (at $-6.0 \mathrm{kcal} / \mathrm{mol}$ ) and it represents the second most stable species among the computationally identified stereoisomeric cyclic intermediates. In contrast to previous two routes, en $+\mathbf{2}$ addition on the $(R, R)$ and $(S, S)$ pathways give cyclobutane intermediates rather than OO species. In these cases, IRC calculations allowed us to characterize high-lying zwitterionic species, which can, however, very easily convert to $\mathrm{CB}$ intermediates (see Figure 5). ${ }^{43}$ The zwitterionic $\mathbf{z w}^{R R}$ and $\mathbf{z w}^{S S}$ species can be regarded as transient (short-lived) intermediates on these reaction 
pathways. Our computations indicate that both $\mathbf{C B}^{R R}$ and $\mathbf{C B}^{S S}$ cyclobutanes can transform into the corresponding $\mathbf{O O}^{R R}$ and $\mathbf{O O}^{S S}$ species via relatively low barriers $(\sim 15$ $\mathrm{kcal} / \mathrm{mol}){ }^{44}$

Scheme 5: Cyclic intermediates formed along the four pathways in the reaction between enamine en and $2 .{ }^{a}$

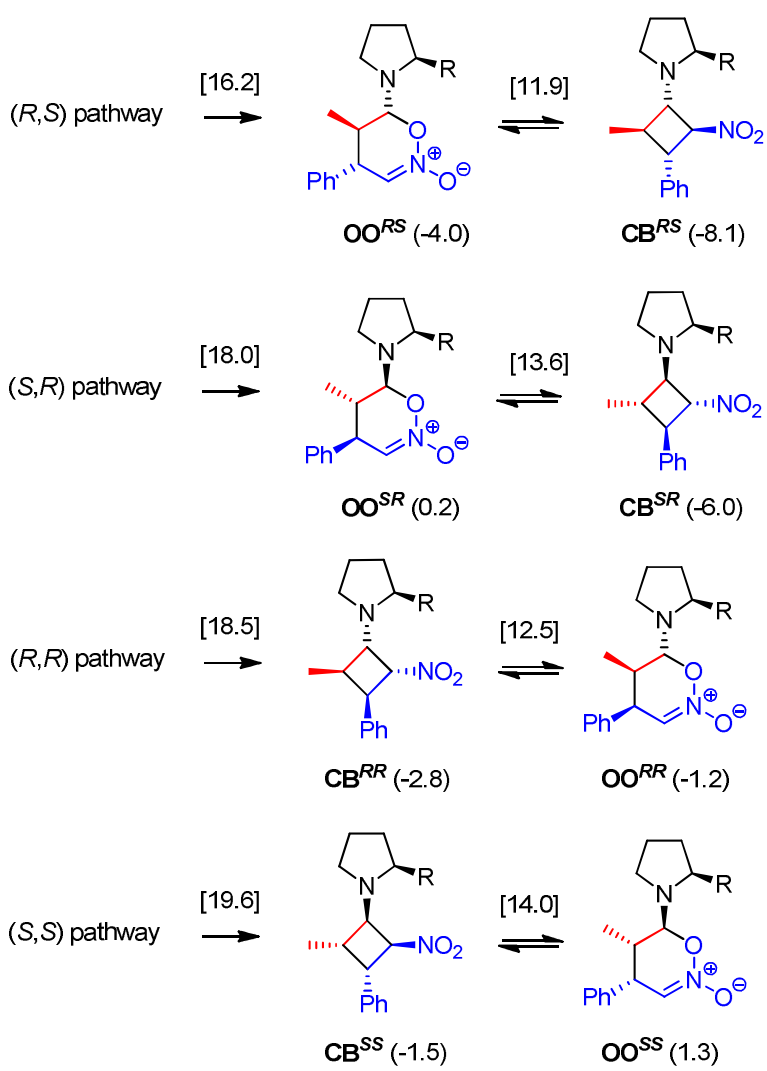

${ }^{\mathrm{a}}$ Relative stabilities are given with respect to reactant state $\mathbf{1}+\mathbf{2}+\mathbf{c a t}(\mathrm{kcal} / \mathrm{mol})$. Data shown in brackets on the arrows refer to relative stabilities of $\mathrm{C}-\mathrm{C}$ bond formation and interconversion transition states (also with respect to $\mathbf{1}+\mathbf{2}+$ cat).

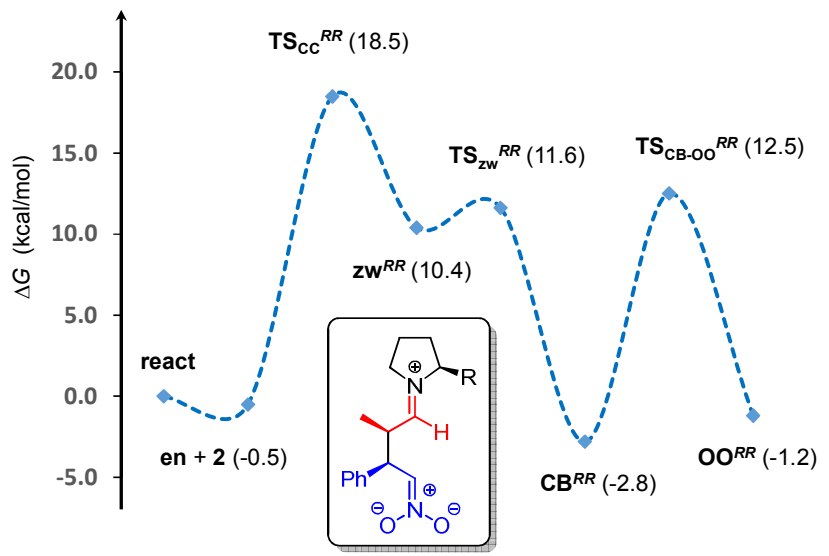

Figure 5: Free energy profile of the $(R, R)$ pathway. Relative stabilities are given with respect to reactant state (in $\mathrm{kcal} / \mathrm{mol})$.
The free energy profiles computed for the four $\mathrm{C}-\mathrm{C}$ bond formation pathways are depicted in Figure 6 for comparison. There are several interesting features worth pointing out in this combined diagram.

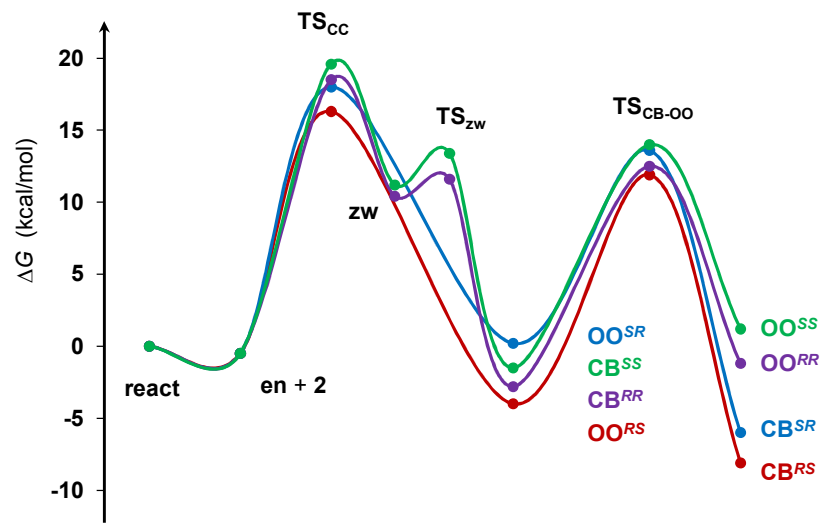

Figure 6: Free energy profiles of the four $\mathrm{C}-\mathrm{C}$ bond formation pathways leading to cyclic intermediates.

As mentioned above, the transition states corresponding to the $\mathrm{C}-\mathrm{C}$ bond formation step on the four stereoisomeric pathways are predicted to be confined in a much narrower free energy window (within $3.4 \mathrm{kcal} / \mathrm{mol}$ ) compared to previous studies. The relative stabilities of cyclic intermediates developed along these pathways cover a significantly broader free energy range (larger than $9 \mathrm{kcal} / \mathrm{mol}$ ), which can be related to the increased steric congestion in the more compact ring structures. Consequently, isomers with alternating trans-trans arrangement of ring substituents (such as in $\mathbf{O O}^{R S}$ or $\mathbf{C B}^{R S}$ ) are more favored, but other stabilizing effects (e.g. electrostatic interactions with the positively charged $\mathrm{SiMe}_{3}$ group) could be important as well. The CB forms of cyclic intermediates are found to be always favored over the related $\mathrm{OO}$ species, but the differences in their relative stabilities appear to be overestimated by the computational method applied herein. ${ }^{45}$ Among the CB isomers, the experimentally observed $\mathbf{C B}^{R S}$ is found to be the most stable form in our computations, but its pseudoenantiomeric form $\mathbf{C B}^{S R}$ is predicted to be thermodynamically feasible as well. It is also apparent from Figure 6 (and from data in Scheme 5) that the barriers of $\mathrm{OO} \leftrightarrow \mathrm{CB}$ interconversions are generally lower than those of corresponding $\mathrm{C}-\mathrm{C}$ bond formation steps (except the $\mathbf{C B}^{R S} \rightarrow \mathbf{O O}^{R S}$ and $\mathbf{C B}^{S R} \rightarrow \mathbf{O O}^{S R}$ transformations), but they are definitely lower than the overall barriers of the reverse reactions back to the $\mathbf{e n}+\mathbf{2}$ state $\left(\mathbf{T S}_{\text {Св-Oo }}\right.$ lies always below the corresponding $\mathbf{T S}_{\mathrm{CC}}$ transition state).

Effect of acid co-catalyst. Previous experimental studies demonstrated that $p$-nitrophenol (pnp) acts as a general additive in Michael additions of propanal to nitroalkenes resulting in rate acceleration while preserving the excellent enantioselectivities. ${ }^{4,5}$ The acid co-catalyst is likely involved in the rate-determining protonation step delivering the proton to one of the cyclic intermediates or to related zwitterionic species. We have 
recently examined possible protonation pathways for the present organocatalytic Michael reaction assuming that pnp is the proton source. ${ }^{5}$ Considering the $(R, S)$ reaction pathway, we found that the proton transfer takes place preferentially to the $C_{3}$ atom of the $\mathbf{O O}^{R S}$ intermediate without the involvement of zwitterionic states. ${ }^{46}$ The barriers obtained for the reactions with $\beta$-nitrostyrene and $\alpha$-methyl-substituted $\beta$-nitrostyrene were consistent with the observed rates, and computations could also reproduce the experimental diastereoselectivity of protonation in the latter case, providing support for this protonation mechanism. In our current work, we examined the $\mathrm{C}-\mathrm{C}$ bond formation process in the presence of pnp for routes $(R, S)$ and $(S, R)$ and followed the corresponding protonation pathways as well. Our main aim was to obtain barriers for the two key steps of the catalytic cycle along the two pathways and correlate them with the proposed stereoselectivity models.

Our calculations indicate that in $\mathrm{C}-\mathrm{C}$ bond formation transition states, the pnp molecule acts as a hydrogen bond donor interacting with the $\mathrm{O}$ atom of the $\beta$ nitrostyrene (see $\mathbf{T S}_{\mathrm{CC}}{ }^{R S} \cdots$ pnp and $\mathbf{T S}_{\mathrm{CC}}{ }^{S R} \cdots$ pnp in Figure 7). Due to the developing charge on the $\mathrm{NO}_{2}$ unit, this interaction becomes stronger in the transition states as compared to en $+\mathbf{2} \cdots \mathbf{p n p}$, so the barrier of the conjugate addition step decreases notably in the presence of pnp (from 16.7 to $14.0 \mathrm{kcal} / \mathrm{mol}$ on route $(R, S)$, and from 18.5 to $17.6 \mathrm{kcal} / \mathrm{mol}$ on $(S, R)) .{ }^{47}$ The computed effect is in line with experimental observations that pnp accelerates the reaction between nitroalkenes and preformed enamines. ${ }^{48}$ The two transition states shown in Figure 7 are predicted to lie at 15.9 and $19.5 \mathrm{kcal} / \mathrm{mol}$ with respect to the reactant state $(\mathbf{1}+\mathbf{2}+$ cat $\cdots \mathbf{p n p})$, which now involves a hydrogenbonded complex formed between the catalyst and the acid. ${ }^{49}$ With this reference level, the overall barriers of $\mathrm{C}$ $C$ bond formation are quite similar to those computed in the absence of pnp (16.2 and $18.0 \mathrm{kcal} / \mathrm{mol}$, see Scheme 5 ), so the overall rates of the formation of cyclic intermediates are not expected to change drastically in the presence of acid co-catalyst...$^{5}$
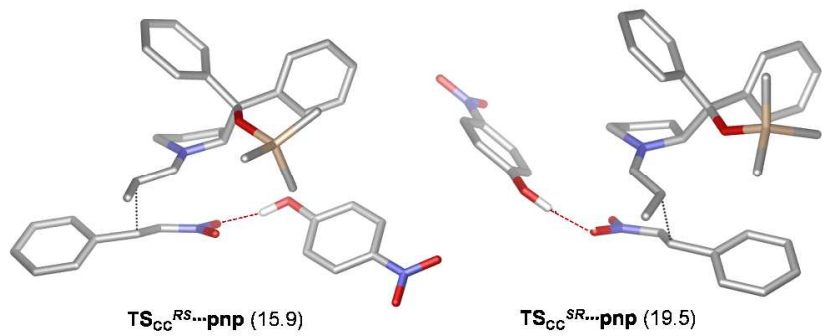

Figure 7: $\mathrm{C}-\mathrm{C}$ bond formation along $(R, S)$ and $(S, R)$ pathways in the presence of pnp. Relative stabilities (in $\mathrm{kcal} / \mathrm{mol}$ ) are given with respect to reactant state $(\mathbf{1}+\mathbf{2}+\mathbf{c a t} \cdots \mathbf{p n p}) . \mathrm{H}-$ bonding interactions are illustrated by red dashed lines.

The product states of the $\mathbf{T S}_{\mathrm{CC}}{ }^{\boldsymbol{R}} \ldots \mathbf{m} \mathbf{p} \mathbf{p}$ and TS $_{\mathrm{CC}}{ }^{S R}$...ppnp transition states correspond to pnp stabilized $\mathrm{OO}$ species $\left(\mathbf{O O}^{R S} \cdots\right.$ pnp and $\mathbf{O O}^{S R} \cdots$ pnp hydrogen-bonded complexes lying at -6.3 and -1.9 $\mathrm{kcal} / \mathrm{mol}$, respectively). Similarly to what we found for the
$(R, R)$ and $(S, S)$ C-C bond formation pathways in the absence of acid, the zwitterionic states of adduct intermediates are energetically high-lying transient species, so the ring closure occurs practically spontaneously in this case too. ${ }^{51} \mathrm{H}$-bonding interactions facilitate the $\mathrm{OO} \rightarrow \mathrm{CB}$ transformations as well. On the $(R, S)$ pathway, for instance, the barrier of $\mathbf{O O}^{R S} \rightarrow \mathbf{C B}^{R S}$ transformation is reduced by $2.3 \mathrm{kcal} / \mathrm{mol}$ (from 15.9 to $13.6 \mathrm{kcal} / \mathrm{mol}$ ) with the pnp co-catalyst. ${ }^{52}$ Interestingly, the H-bonded $\mathbf{C B}^{R S} \ldots$ pnp and $\mathbf{C B}^{S R} \cdots$ pnp complexes are slightly less stable than their dissociated forms $\left(\mathbf{C B}^{R S}+\right.$ pnp and $\mathbf{C B}^{S R}+$ pnp are computed to be at -5.8 and -3.6 $\mathrm{kcal} / \mathrm{mol}$, whereas the corresponding complexes are at 3.7 and $-3.4 \mathrm{kcal} / \mathrm{mol}$ with respect to reactant state).

Our conformational analysis revealed an array of closelying transition states for the protonation of $\mathbf{O O}^{R S}$ and OO $^{S R}$ intermediates, and the most stable structures are depicted in Figure $8 .^{53}$ All these transition states describe a concerted asynchronous mechanism, wherein the opening of the six-membered ring precedes the proton transfer event but without a discrete intermediate species. On the $(R, S)$ pathway, the located transition state $\left(\mathrm{TS}_{\text {prot }}{ }^{R S}\right)$ is predicted to lie only at $11.8 \mathrm{kcal} / \mathrm{mol}$ in free energy (relative to the reactant level), but the barrier of this protonation process is $18.1 \mathrm{kcal} / \mathrm{mol}$ with respect to the most stable intermediate state (i.e. the $\mathbf{O O}^{R S} \cdots \mathbf{p n p}$ H-bonded complex). On the $(S, R)$ pathway, the $\mathbf{T S}_{\text {prot }}$ transition state is computed to be notably higher in free energy (at $15.1 \mathrm{kcal} / \mathrm{mol}$ ), but the protonation barrier on this route $(18.7 \mathrm{kcal} / \mathrm{mol})$ is similar to that found for the $(R, S)$ route. We note that on both protonation pathways the proton donor co-catalyst is in close contact with different units of the developing iminium ion, which provides additional stabilization for the transition states (see Figure 8), however, the relative stabilities of the two protonation transition states are primarily determined by the stabilities of the corresponding $\mathbf{O O}^{\boldsymbol{R S}}$ and $\mathbf{O O}^{S R}$ intermediates.
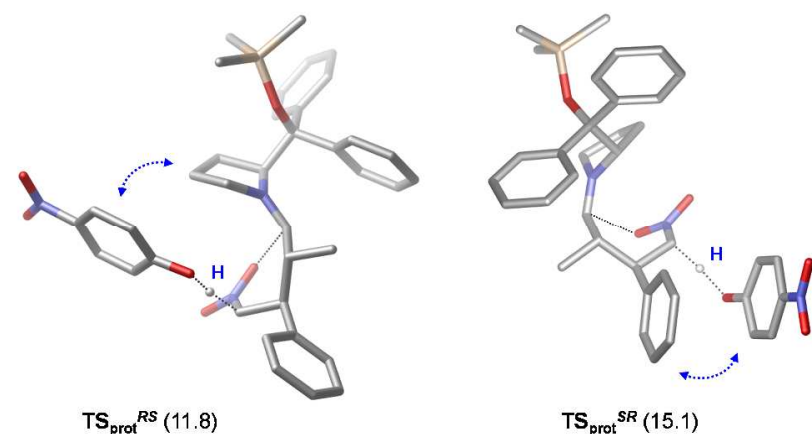

Figure 8: Protonation of $\mathbf{O O}^{R S}$ and $\mathbf{O O}^{S R}$ species by pnp. Relative stabilities (in $\mathrm{kcal} / \mathrm{mol}$ ) are given with respect to reactant state $(\mathbf{1}+\mathbf{2}+$ cat $\cdots$ pnp $)$. Hydrogen involved in proton migration is marked with blue $\mathrm{H}$. Intermolecular contacts between the co-catalyst and different units of the developing iminium ion are highlighted by blue arrows.

Relation to selectivity models. The free energy data computed for the $(R, S)$ and $(S, R)$ pathways of the investigated Michael reaction are summarized in Figure 9. 
Both pathways involve the two basic steps of the catalytic cycle ( $\mathrm{C}-\mathrm{C}$ bond formation and protonation) connected with the ensemble of $\mathrm{OO} / \mathrm{CB}$ intermediates, of which only the most stable states are shown $\left(\mathbf{O O}^{R S}\right.$...pnp on the major and $\mathbf{C B}^{S R}+$ pnp on the minor pathway). ${ }^{54}$

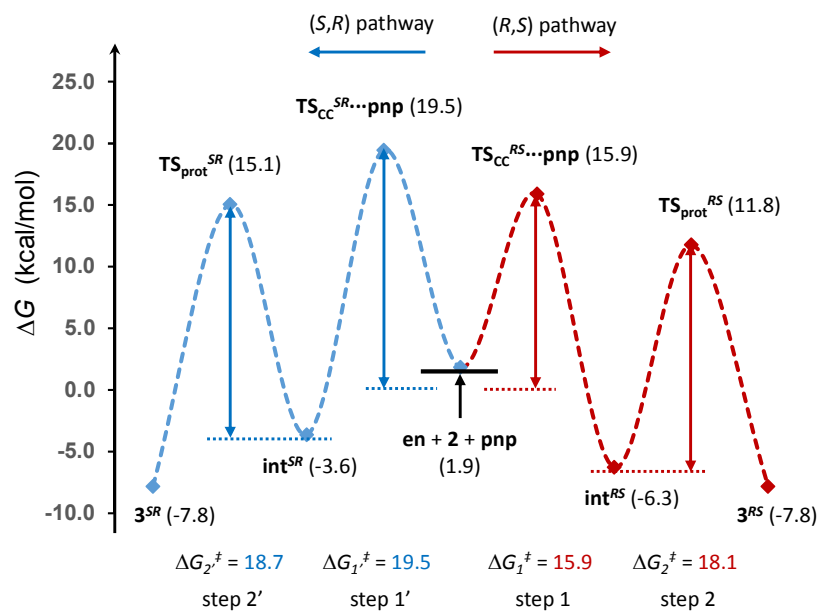

Figure 9: Free energy profile computed for the $(R, S)$ and $(S, R)$ pathways of reaction $\mathbf{1}+\mathbf{2} \rightarrow \mathbf{3}$ catalyzed by cat and pnp. Relative stabilities (in $\mathrm{kcal} / \mathrm{mol}$ ) are given with respect to reactant state $(\mathbf{1}+\mathbf{2}+\mathbf{c a t} \cdots \mathbf{p n p})$. For both pathways, only the most stable states of cyclic intermediates are indicated (for simplicity, they are denoted as int ${ }^{R S}$ and int ${ }^{S R}$ ). $\Delta G_{1}^{\ddagger}$ and $\Delta G_{2}^{\ddagger}$ data refer to barriers of the two basic steps on the major pathway, whereas $\Delta G_{1}^{\prime \neq}$ and $\Delta G_{2}{ }^{\prime \neq}$ to those on the minor route.

We note first that the main attributes of the obtained diagram are in good agreement with the observations of experimental mechanistic studies. Computations predict a fast and stereospecific formation of cyclic intermediates $\left(\mathbf{O O}^{R S}\right.$ and $\left.\mathbf{C B}^{R S} ; \Delta G_{1}^{\ddagger}=15.9 \mathrm{kcal} / \mathrm{mol}\right)$ that are rather stable and therefore experimentally observable. The subsequent protonation step towards the major product has a larger barrier $\left(\Delta G_{2}^{\ddagger}=18.1 \mathrm{kcal} / \mathrm{mol}\right)$, so $\mathbf{T S}_{\text {prot }}{ }^{R}$ represents the turnover-determining transition state on this route. The backward reaction from the cyclic intermediates to $\mathbf{e n}+\mathbf{2}$ is kinetically feasible as well (the calculated barrier is $22.2 \mathrm{kcal} / \mathrm{mol}$ ), but in our computations, the protonation process is predicted to be faster as the corresponding transitions state $\left(\mathrm{TS}_{\mathrm{prot}}{ }^{R S}\right)$ lies well below $\mathbf{T S}_{\mathrm{CC}}{ }^{R S} \ldots$ pnp. ${ }^{55}$ On the $(S, R)$ pathway, the formation of the $\mathbf{O O}^{S R}$ and $\mathbf{C B}^{S R}$ cyclic species takes place via significantly higher barrier $\left(\Delta G_{1}^{\ddagger}=19.5 \mathrm{kcal} / \mathrm{mol}\right)$, which, in fact, slightly exceeds the corresponding protonation barrier as well $\left(\Delta G_{2}^{\ddagger}=18.7 \mathrm{kcal} / \mathrm{mol}\right)$. These barriers are quite comparable, so no clear conclusion can be drawn as to which step is rate-determining on this pathway. Although the reverse process to $\mathbf{e n}+\mathbf{2}$ is still viable (through a barrier of $23.1 \mathrm{kcal} / \mathrm{mol}$ ), the protonation is again more favored kinetically.

On the basis of the overall free energy diagram, it is by no means straightforward to associate the stereoselectivity of the present reaction with a single elementary step as implied by the two stereoselectivity models proposed in the literature (see Figure 1). The computed free energy profile strongly suggests, however, that the diastereomeric cyclic intermediates formed in the present reaction cannot be regarded as rapidly interconverting intermediates. The Curtin-Hammett conditions are not met because the int ${ }^{R S}$ intermediates evolving on the major pathway are not able to equilibrate with the int ${ }^{S R}$ isomers for two reasons: a) the kinetic barrier of the int ${ }^{R S} \rightarrow$ int $^{S R}$ transformation on the reverse pathway is relatively high $(25.8 \mathrm{kcal} / \mathrm{mol}$ via TS $_{\mathrm{CC}}{ }^{S R}$....pnp); b) the int ${ }^{R S}$ intermediates would rather undergo protonation via $\mathbf{T S}_{\text {prot }}{ }^{\boldsymbol{R}}$ and then hydrolysis to yield the major product $\left(3^{R S}\right)$. These results thus do not support the Curtin-Hammett stereocontrol model proposed by Blackmond et al. The obtained free energy profile is actually more compatible with the steric shielding model, because it suggests that the $\mathrm{C}-\mathrm{C}$ bond formation step is decisive in stereocontrol even though the overall reaction rate is regulated in an ensuing reaction step of the catalytic cycle. In other words, the elementary step controlling the enantioselectivity does not coincide with the rate-determining step in the present catalytic cycle. ${ }^{56}$ This kinetic feature is clearly related to the high stability of downstream OO/CB intermediates, which does not allow a fast backward reaction and make the C-C bond formation practically irreversible.

Relevance to back reaction screening experiments. As noted in the introduction, the findings of mass spectrometric studies reported by Pfaltz and Wennemers were suggested to support the Curtin-Hammett scenario of stereocontrol ${ }^{10}$ so it is relevant to relate our results to the experimental observations. In these experiments, the back reaction of mass-labeled quasi-enantiomeric nitroaldehyde products was monitored by electrospray ionization mass spectrometry (ESI-MS). The high sensitivity of this analytic technique enabled the detection of enamine intermediates produced upon the retro-Michael reaction with various chiral amine catalysts, and the measured ratio of the two massspectrometrically distinguishable enamines could be used to determine the enantioselectivity of the back reaction.

For tripeptide catalysts bearing a carboxylic acid moiety, ${ }^{57}$ the measured ratios were in excellent agreement with the enantioselectivities of the preparative forward reactions between 3-phenylpropanal (4) and $\beta$ nitrostyrene (2) supporting the concept that the properly positioned carboxylic acid group of the tripeptide facilitates the protonation step, so $\mathrm{C}-\mathrm{C}$ bond formation becomes turnover-limiting. Similar back reaction screening experiments with the Jørgensen-Hayashi catalyst (cat) gave significant differences in the enantioselectivities of the forward and back reactions (an example is shown in Scheme 6). The observed mismatch in this latter case was interpreted as an evidence that the stereoselectivity is not governed by the C-C bond formation between the enamine and the nitroalkene, but instead it is determined in the protonation step, which would indeed be in line with the Curtin-Hammett stereocontrol model. 
Scheme 6: Results of back reaction screening with the Jørgensen-Hayashi catalyst (cat). ${ }^{a}$

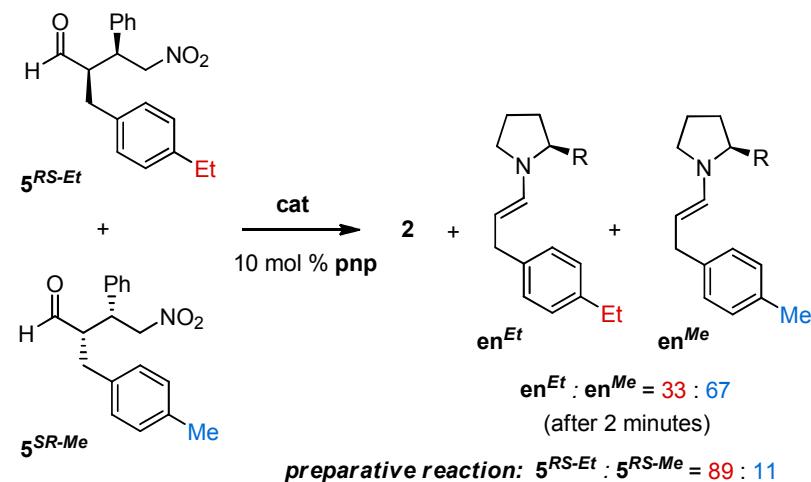

${ }^{\mathrm{a}}$ Groups used in mass labelling (Et and Me) are highlighted in colors.

The free energy profile we obtained for the $\mathbf{1}+\mathbf{2} \rightarrow \mathbf{3}$ reaction (Figure 9) suggests that both steps of the back reaction are reversible, and the individual barriers on the pathways back to the enamine intermediate are quite comparable (see Figure 10 for comparison). ${ }^{58}$ Consequently, the ratio of labeled enamines formed in the back reaction might not be anticipated simply from the free energy data, but a more elaborate kinetic analysis that takes into account the population of all involved states (concentration effects) is required. To this end, we have performed kinetic simulations using the COPASI package. ${ }^{59}$ This modelling tool provides numerical solutions to the differential rate equations and allows us to derive kinetic profiles and to follow the concentration of all species over the course of the reaction.

In our kinetic models, the rate equations were defined according to the present two-step scheme, but also including the fast equilibrium between the aldehyde + cat and enamine $+\mathrm{H}_{2} \mathrm{O}$ states. The rate constants were expressed in terms of free energy differences and they were varied and optimized so as to reproduce the experimental observations and get minimal deviation from an arbitrarily chosen free energy profile. Various sets of kinetic parameters reflecting the qualitative features of the computed free energy diagram were tested, and they could all reproduce the mismatch in the enantioselectivity of the forward and back reactions observed in the ESI-MS back reaction screening experiments. ${ }^{60}$

For instance, parameter optimization using the computed free energies as a reference data set and experimental data reported for the analogue reaction (Scheme 6) gave only slight deviations from the reference free energy values. As indicated in Figure 10, the largest deviations are only 1.1-1.2 kcal $/ \mathrm{mol}$. The free energies of $\mathrm{C}-\mathrm{C}$ bond formation transition states adjust well to the enantioselectivity measured for the preparative reaction. With the optimized data, $\Delta \Delta G_{1}^{\ddagger}=1.3 \mathrm{kcal} / \mathrm{mol}$, which corroborates that the stereoselectivity of the forward reaction is indeed governed by the $\mathrm{C}-\mathrm{C}$ bond formation step. The barriers of the back reaction vary by less than
$2.5 \mathrm{kcal} / \mathrm{mol}$ as well, and interestingly, the barrier of C-C cleavage on the major $(R, S)$ pathway becomes clearly higher than the other barriers towards the enamine species (see $\Delta G_{-1}{ }^{\ddagger}=23.3 \mathrm{kcal} / \mathrm{mol}$ in Figure 10). ${ }^{61}$ The increased barrier of this step delays the production of enamine along this pathway, particularly in the initial phase of the reaction, when the concentrations of the downstream intermediates are low. This is clearly borne out by the kinetic simulations as illustrated in Figure 11.

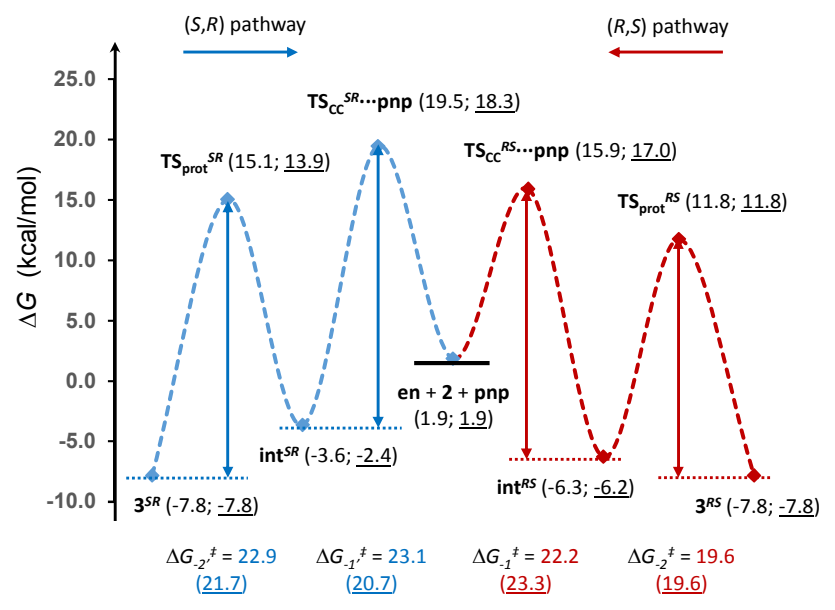

Figure 10: Computed free energy profile highlighting the barriers of the $\mathbf{3} \rightarrow \mathbf{e n}+\mathbf{2}$ back reaction $\left(\Delta G_{-1}^{\ddagger}\right.$ and $\Delta G_{-2}^{\ddagger}$ on the major, $\Delta G_{-1^{\prime}}{ }^{\ddagger}$ and $\Delta G_{-2^{\prime}}{ }^{\ddagger}$ on the minor pathways). Underlined values were obtained from kinetic simulations (see text below).

The graph depicted in Figure 11a reveals a strong variation in the concentrations of the catalyst and the major $(R, S)$ cyclic intermediate in the back reaction, and they both reach a constant value (i.e. the steady state) in about an hour. The concentration of the minor $(S, R)$ intermediate remains very low in accordance with the relative stabilities. The progress of the simulated enantioselectivities is shown in Figure $11 b$ along with the experimental data. We recall that the enantioselectivity of the preparative reaction is determined at near completion of the Michael process, ${ }^{62}$ but the ESI-MS measurements for the back reaction are carried out within short time from the beginning of the reaction (in 2 minutes in the present case). Simulations reproduce the measured selectivities, however, the graph reveals strong variation of this property in the initial stages of the two reactions both starting with reversed sense of stereoselection as compared to that of the preparative reaction. In the forward reaction, the enantiomeric ratio (er) converges rapidly to the 89:11 asymptote, whereas this limit is reached much latter in the back reaction.

We note that all our attempts to reproduce the experimental selectivity data and the observed mismatch with free energy profiles compatible with the steric shielding and the Curtin-Hammet models have failed in that the free energy parameters obtained from optimization were not consistent with these models. ${ }^{63}$ 
a)

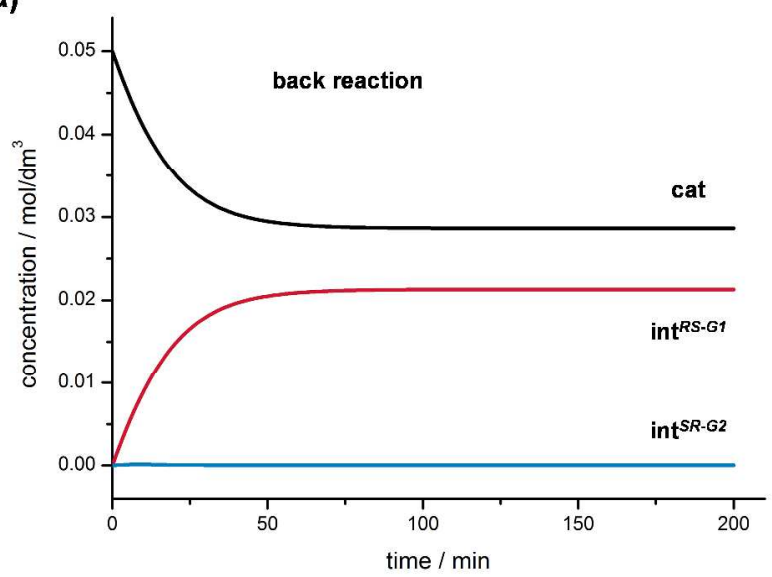

b)

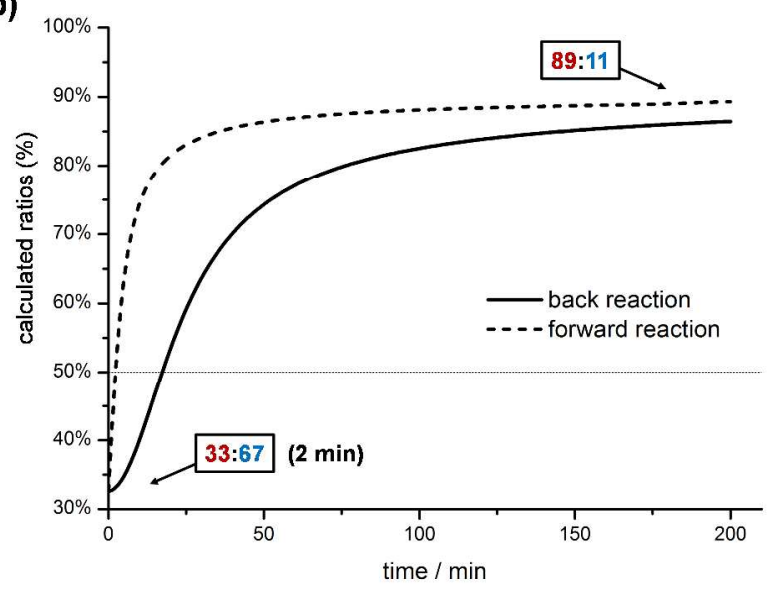

Figure 11: Results of kinetic simulations: a) Concentration of selected species as a function of time in the back reaction as obtained from kinetic simulations using the optimized free energy data shown in Figure 10. b) Evolution of enantiselectivities in the back and forward reactions. The vertical axis refers to the percentage of the species (product or enamine) formed upon the major $(\mathrm{R}, \mathrm{S})$ pathway. Experimental observations are given in boxes. These data are taken from ref. 1oa and they refer to reactions carried out with $10 \mathrm{~mol} \%$ of para-nitrophenol additive.

Based on these results we propose an alternative rationalization of the enantioselectivity mismatch observed in back reaction screening experiments for reactions catalyzed by the Jørgensen-Hayashi catalyst. In this alternative view, the mismatch is not related to rapid equilibration of downstream intermediates, but on the contrary, it is rather due to relatively high barrier from the downstream intermediates to the enamine species, which is comparable, or even higher than that associated with the protonation step. In the initial phase of the back reaction, the enantioselectivity does not depend only on the $\mathrm{C}-\mathrm{C}$ bond formation transition states, but also on the stability of downstream intermediates and on the rate of their formation resulting in time dependence in the enantioselectivity. ${ }^{6}{ }^{4}$ With kinetic models that assume much lower barrier either for step 2 (steric shielding model) or for step 1 (Curtin-Hammett scenario), the steady state of the catalytic reaction is reached almost instantaneously, and in the steady state regime, the enantioselectivity of the back reaction is identical to that of the forward process. ${ }^{65}$

Experimental evidence for time-dependent enantioselectivity of the back reaction. To our knowledge, no experimental information is available on the variation of the enantioselectivity during the progress of the back reaction, so we intended to examine this issue via ESI-MS measurements. We prepared the $(R, S)$ and $(S, R)$ stereoisomers of nitroaldehyde $\mathbf{5}$ with $\mathrm{Me}$ and $\mathrm{Et}$ substituents in the para-position of the phenyl ring, respectively (see Scheme 6), from corresponding aldehydes and $\beta$-nitrostyrene using the catalyst cat and its enantiomer ent-cat. ${ }^{66}$ When these Michael additions were carried out in DMSO with $10 \mathrm{~mol} \%$ of catalyst cat and $10 \mathrm{~mol} \%$ of pnp additive, we obtained $\mathrm{er}=91: 9$ $\left(5^{R S} / 5^{S R}\right)$, which is in close agreement with that reported by Pfaltz and Wennemers. ${ }^{10 a}$

The back reaction was carried out under the same conditions starting from an equimolar mixture of masslabeled nitroaldehydes $\left(5^{R S-M e}\right.$ and $5^{S R \text {-Et }}$ in our case). This reaction was monitored by ESI-MS measurements using samples taken at different times from the reaction mixture and diluted with $\mathrm{MeOH}$ prior to the analysis. The ESI-MS signals of mass-labeled enamines $\left(\mathbf{e n}^{\mathrm{Me}}\right.$ and $\mathbf{e n}^{\mathrm{Et}}$ ) formed upon the reaction could be clearly detected, and based on their relative intensities, the enantiomeric ratios were determined. Two independent back reaction screening experiments were carried out using the same substrates, but altering the catalyst (cat and ent-cat). The results are compiled in Figure 12.

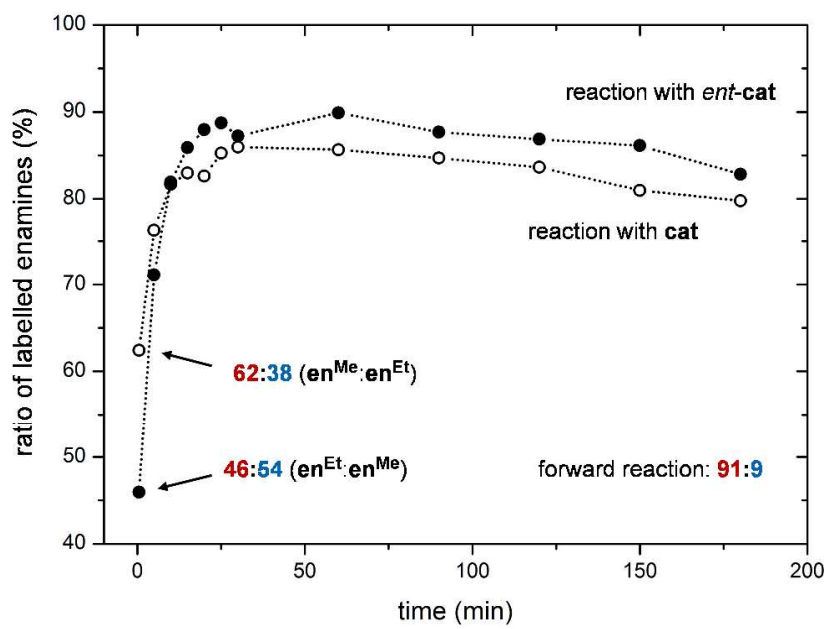

Figure 12: Ratios of labeled enamines measured in back reaction screening experiments. Empty and full dots correspond to data obtained in the reaction with catalyst cat and ent-cat, respectively. The enantiomeric ratio indicated on the vertical axis refers to the percentage of mass-labeled enamine species formed upon the major $(R, S)$ pathway of the back reaction. Ratios measured for the first sample (taken at $t=0.5 \mathrm{~min}$ ) as well as the er of the forward reaction are displayed in color.

In line with previous observations, ${ }^{\text {10a }}$ the ratio of masslabeled enamines at the very early stage of the back 
reaction (at $t=0.5 \mathrm{~min}$ in our case) differs significantly from the er of the forward process (91:9). The two independent measurements gave 62:38 and 46:54 with catalysts cat and ent-cat), which are in reasonable agreement with the previously reported ratio (33:67), although these findings point to quite notable uncertainty of the present enantioselectivity monitoring technique for the initial phase of the back reaction, which is quite likely related to particular reaction conditions. ${ }^{67}$ As predicted by kinetic simulations, the enantiomeric ratio varies strongly in this period and it approaches the er of the forward reaction. After 50 minutes or so, the ratio tends to decrease again indicating that racemization occurs in the reaction mixture. These results provide clear evidence for the time variance of the ratio of mass-labeled enamine species produced in the retro-Michael reaction, which is not due to the racemization of quasi-enantiomeric Michael products, but it rather follows from the special kinetic feature revealed in our present work. ${ }^{68}$ The more complex stereoselectivity model that emerged from our computational analysis and kinetic simulations could thus be supported experimentally.

\section{SUMMARY AND CONCLUSIONS}

Recent mechanistic investigations on conjugate addition reactions catalyzed by the Jørgensen-Hayashi chiral amine have contributed to our understanding of the basic steps of enamine catalysis, but they have also brought up several controversial issues. In our present work, we assessed the validity of two conflicting stereoselectivity models via computational analysis carried out for the Michael addition of propanal to $\beta$ nitrostyrene. We focused on two key elementary steps of the catalytic cycle that are known to govern the rate and the stereoselectivity, namely on the C-C bond formation and the subsequent protonation events.

The transition states and reaction intermediates involved in these processes are conformationally complex species, and a reliable structural and energetic characterization requires a thorough conformational sampling. Conformational changes related to the puckering of the pyrrolidine ring and the orientation of the bulky substituent of the catalyst are kinetically allowed, so the conformational search should cover these degrees of freedom as well. Computations disregarding this component of conformational complexity may lead to significant inaccuracy in stereoselectivity predictions.

The most favored transition states identified along the four different stereoisomeric C-C bond formation pathways are consistent with the common steric shielding model as the addition preferentially occurs on the unhindered face of the E-enamine intermediate. The $\mathrm{NO}_{2}$ group of the approaching $\beta$-nitrostyrene is always in the close proximity of the pyrrolidine ring, which enables a facile ring closure straight after the $\mathrm{C}-\mathrm{C}$ bond formation either leading directly to cyclic OO and $\mathrm{CB}$ intermediates, or involving transient zwitterionic intermediates before ring closure. The interconversion of these downstream intermediates takes place in a single step through relatively low barriers. The acid co-catalyst pnp stabilizes the transition states of both $\mathrm{C}-\mathrm{C}$ bond formation and $\mathrm{OO}$ $\leftrightarrow \mathrm{CB}$ interconversion steps via $\mathrm{H}$-bonding interactions lowering the related barriers.

The mechanism of the protonation process has not been fully established in previous works, but the computational analysis offers a plausible pathway. Accordingly, the stereoisomeric OO species can be protonated by the acid co-catalyst producing iminiumphenolate ion-pair intermediates. The computed protonation barrier, at least for the formation of the major stereoisomeric product, is notably higher than that of the preceding addition step, which is in line with experimental observations that classify the protonation to be rate-determining. The transition states of proton transfer processes lie well below the corresponding C-C bond formation transition states, implying that fast equilibration of the stereoisomeric cyclic intermediates is inconceivable, which rules out the Curtin-Hammett steroselectivity control in this reaction. The reaction rate is dictated by the protonation step, but yet the stereoselectivity is determined before by the C-C bond formation transition states. It therefore seems that the originally proposed and the widely used steric shielding model is still applicable for the present Michael reaction. Introducing various substituents in the reactants $\left(R^{1}\right.$ and $\mathrm{R}^{2}$ in Scheme 1) can of course greatly influence the stability of downstream intermediates and also the barrier heights of the two key steps of the catalytic cycle, so further computational and experimental studies are required to assess the generality of these conclusions. Investigations along these lines are in progress in our laboratories and we think they may clarify other mechanistic disagreements as well.

The back-reaction screening method is a valuable tool for evaluating the enantioselectivity determining step for the vast majority of reactions. However, the interpretation of the results obtained for the reaction examined herein required revision in light of the kinetic scenario revealed in our present work. Our detailed kinetic analysis suggests that the experimentally observed mismatch in the enantioselectivities of the forward and back reactions cannot be interpreted in terms of simple stereoselectivity models that associate the stereocontrol with a single elementary step (i.e. C-C bond formation or protonation), but a two-step scheme with qualitative features described above provides a reasonable explanation for these observations as well. The delicate balance between the barriers on the competitive stereoisomeric pathways in the back reaction determines the initial ratio of mass-labeled enamines, which can differ from that measured for the preparative reaction. According to this kinetic scheme, the enantioselectivity of the retro-Michael process is expected to vary in time along the reaction course and approach the enantioselectivity of the forward reaction, which could be demonstrated experimentally in our present work. 


\section{ASSOCIATED CONTENT}

Supporting Information: Details regarding the computational analysis and kinetic simulations, total energies and Cartesian coordinates for the considered stationary points, and experimental details. This material is available free of charge via the Internet at http://pubs.acs.org.

\section{AUTHOR INFORMATION}

\section{Corresponding Author}

*papai.imre@ttk.mta.hu

\section{ACKNOWLEDGMENT}

Financial support for this work was provided by the Hungarian Scientific Research Fund (OTKA, grant K-112028), the National Research, Development and Innovation Office (NKFIH, grant PD-121070), and the UNKP-17-4-II New National Excellence Program of the Ministry of Human Capacities. Á. M. and Sz. V. acknowledge the János Bolyai Scholarship from Hungarian Academy of Sciences. Computer facilities provided by NIIF HPC Hungary (project 85708 kataproc) is also acknowledged. We are grateful to Dr. Tibor András Rokob and to Dr. Sahoo Gokarneswar for insightful discussions.

\section{REFERENCES}

(1) For pioneering works, see: (a) Marigo, M.; Wabnitz, T. C.; Fielenbach, D.; Jørgensen, K. A. Angew. Chem. Int. Ed. 2005, 44, 794-797. (b) Hayashi, Y.; Gotoh, H.; Hayashi, T.; Shoji, M. Angew. Chem. Int. Ed. 2005, 44, 4212-4215. (c) Franzén, J.; Marigo, M.; Fielenbach, D.; Wabnitz, T. C.; Kjærsgaard, A.; Jørgensen K. A. J. Am. Chem. Soc. 2005, 127, 18296-18304.

(2) For reviews, see: (a) Donslund, B. S.; Johansen, T. K.; Poulsen, P. H.; Halskov, K. S.; Jørgensen, K. A. Angew. Chem., Int. Ed. 2015, 54, 1386o-13874. (b) Jensen, K. L.; Dickmeiss, G.; Jiang, H.; Albrecht, Ł.; Jørgensen, K. A. Acc. Chem. Res. 2012, 45, 248-264. (c) Ishikawa, H.; Honma, M.; Hayashi, Y. Angew. Chem. Int. Ed. 2011, 50, 2824-2827. (d) Hayashi, Y. Chem. Sci. 2016, 7, 866-880.

(3) (a) Burés, J.; Armstrong, A.; Blackmond, D. G. J. Am. Chem. Soc. 2011, 133, 8822-8825. (b) Burés, J.; Armstrong, A.; Blackmond, D. G. J. Am. Chem. Soc. 2012, 134, 6741-6750.

(4) (a) Patora-Komisarska, K.; Benohoud, M.; Ishikawa, H.; Seebach, D.; Hayashi, Y. Helv. Chim. Acta 2011, 94, 719-745. (b) Seebach, D.; Sun, X.; Sparr, C.; Ebert, M.-O.; Schweizer, W. B.; Beck, A. K. Helv. Chim. Acta 2012, 95, 1064-1078. (c) Seebach, D.; Sun, X.; Ebert, M.-O.; Schweizer, W. B.; Purkayastha, N.; Beck, A. K.; Duschmale, J.; Wennemers, H.; Mukaiyama, T.; Benohoud, M.; Hayashi, Y.; Reiher, M. Helv. Chim. Acta 2013, 96, 799-852.

(5) Sahoo, G.; Rahaman, H.; Madarász, A.; Pápai, I.; Melarto, M.; Valkonen, A.; Pihko, P. M. Angew. Chem., Int. Ed. 2012, 51, 13144-13148.

(6) For reviews highlighting controversial issues, see: (a) Moberg, C. Angew. Chem., Int. Ed. 2013, 52, 2160-2162. (b) Holland, M. C.; Gilmour R. Angew. Chem., Int. Ed. 2015, 54, 38623871. (c) Burés, J.; Armstrong, A.; Blackmond, D. G. Acc. Chem. Res. 2016, 49, 214-222.

(7) The advantageous effect of Brønsted acid additives in Michael reactions catalyzed by other chiral amines has also been documented: (a) Alexakis, A.; Andrey, O. Org. Lett. 2002, 4, 3611-3614. (b) Mase, N.; Thayumanavan, R.;Tanaka, F.; Barbas, C. F. Org. Lett. 2004, 6, 2527-2530. (c) Ishii, T.; Fujioka, S.; Sekiguchi, Y.; Kotsuki, H. J. Am. Chem. Soc. 2004, 126, 9558-9559. (d) Wiesner, M.; Upert, G.; Angelici, G.; Wennemers, H. J. Am Chem. Soc. 2010, 132, 6-7. (e) Saha, S.; Seth, S.; Moorthy, J. N. Tetrahedron Lett. 2010, 51, 5281-5286. (f) Zheng, Z.; Perkins, B. L.; Ni, B. J. Am. Chem. Soc. 2010, 132, 50-51.

(8) In the case of linear aldehydes, the deprotonation of iminium intermediate gives rise to enamine species also observed experimentally. The role of product enamine in the catalytic cycle is also debated, but this mechanistic issue was not addressed in our present work.

(9) Seebach, D.; Golinski, J. Helv. Chim. Acta 1981, 64, 14131423.

(10) (a) Bächle, F.; Duschmalé, J.; Ebner, C.; Pfaltz, A.; Wennemers, H. Angew. Chem., Int. Ed. 2013, 52, 12619-12623. (b) Isenegger, P. G.; Pfaltz, A. Chem. Rec. 2016, 16, $2534-2543$.

(11) For reviews, see: (a) Cheong, P. H.; Legault, C. Y.; Um, J. M.; Çelebi-Ölçüm, N. C.; Houk, K. N. Chem. Rev. 2011, 111, 50425137. (b) Pápai I. In Science of Synthesis. Asymmetric Organocatalysis 2; Maruoka, K., Ed.; Thieme Stuttgart: New York, 2012; p. 601.

(12) Halskov, K. S.; Donslund, B. S.; Pazand, B. M.; Jørgensen, K. A. Acc. Chem. Res. 2016, 49, 974-986.

(13) For a recent tutorial review on concepts and challenges in computing stereoselectivities, see: Peng, Q.; Duarte, F.; Paton, R. S. Chem. Soc. Rev. 2016, 45, 6093-6107.

(14) Shinisha, C. B.; Sunoj, R. B. Org. Biomol. Chem. 2oo8, 6, 3921-3929.

(15) Zhao, J.-Q.; Gan L.-H. Eur. J. Org. Chem. 2oo9, 2661-2665.

(16) Armstrong, A.; Boto, R. A.; Dingwall, P.; ContrerasGarcía, J.; Harvey, M. J.; Mason, N. J.; Rzepa, H. S. Chem. Sci. 2014, 5, 2057-2071.

(17) Conformational complexity related to the pyrrolidine ring and the orientation of the bulky substituent is of similar concern in iminium catalysis as well. For an example highlighting this issue, see: Claraz, A.; Sahoo, G.; Berta, D.; Madarász, Â.; Pápai, I.; Pihko, P. M. Angew. Chem., Int. Ed. 2016, $55,669-673$.

(18) MacroModel, Schrödinger, LLC, New York, NY, 2016.

(19) (a) Chai, J.-D.; Head-Gordon, M. Phys. Chem. Chem. Phys. 2008, 10, 6615-6620. (b) Chai, J.-D.; Head-Gordon, M. J. Chem. Phys. 2008, 128, 084106. (c) Grimme, S. J. Comput. Chem. 2006, 27, 1787-1799.

(20) For the 6-311G(d,p) and 6-311++G(3df,3pd) basis sets, see: (a) Krishnan, R.; Binkley, J. S.; Seeger, R.; Pople, J. A. J. Chem. Phys. 1980, 72, 650-654. (b) McLean, A. D.; Chandler, G. S. J. Chem. Phys. 1980, 72, 5639-5648. (c) Clark, T.; Chandrasekhar, J.; Spitznagel, G. W.; Schleyer, P. v. R. J. Comput. Chem. 1983, 4, 294-301. (d) Frisch, M. J.; Pople, J. A.; Binkley, J. S. J. Chem. Phys. 1984, 8o, 3265-3269.

(21) Gaussian o9, Revision D.o1, Frisch, M. J.; Trucks, G. W.; Schlegel, H. B.; Scuseria, G. E.; Robb, M. A.; Cheeseman, J. R.; Scalmani, G.; Barone, V.; Mennucci, B.; Petersson, G. A.; Nakatsuji, H.; Caricato, M.; Li, X.; Hratchian, H. P.; Izmaylov, A. F.; Bloino, J.; Zheng, G.; Sonnenberg, J. L.; Hada, M.; Ehara, M.; Toyota, K.; Fukuda, R.; Hasegawa, J.; Ishida, M.; Nakajima, T.; Honda, Y.; Kitao, O.; Nakai, H.; Vreven, T.; Montgomery, J. A., Jr.; Peralta, J. E.; Ogliaro, F.; Bearpark, M.; Heyd, J. J.; Brothers, E.; Kudin, K. N.; Staroverov, V. N.; Kobayashi, R.; Normand, J.; Raghavachari, K.; Rendell, A.; Burant, J. C.; Iyengar, S. S.; Tomasi, J.; Cossi, M.; Rega, N.; Millam, J. M.; Klene, M.; Knox, J. E.; Cross, J. B.; Bakken, V.; Adamo, C.; Jaramillo, J.; Gomperts, R.; Stratmann, R. E.; Yazyev, O.; Austin, A. J.; Cammi, R.; Pomelli, C.; Ochterski, J. W.; Martin, R. L.; Morokuma, K.; Zakrzewski, V. G.; Voth, G. A.; Salvador, P.; Dannenberg, J. J.; Dapprich, S.; Daniels, A. D.; Farkas, Ö.; Foresman, J. B.; Ortiz, J. V.; Cioslowski, J.; Fox, D. J. Gaussian, Inc., Wallingford CT, 2009. 
(22) (a) Hratchian, H. P.; Schlegel, H. B. J. Chem. Phys. 2004, 120, 9918-9924. (b) Hratchian, H. P.; Schlegel, H. B. J. Chem. Theory Comput. 2005, 1, 61-69.

(23) Tomasi, J.; Mennucci, B.; Cancès, E. J. Mol. Struct. (Theochem) 1999, 464, 211-226.

(24) Marenich, A. V.; Cramer, C. J.; Truhlar, D. G. J. Phys. Chem. B 2009, 113, 6378-6396.

(25) Corresponding data for toluene are reported in the Supporting Information.

(26) Goerigk, L.; Grimme, S. Phys. Chem. Chem. Phys. 2011, 13, 6670-6688.

(27) For experimental background, see: Seebach, D.; Beck, A. K.; Golinski, J.; Hay, J. N.; Laube, T. Helv. Chim. Acta 1985, 68, 162-172.

(28) (a) Nagy, P. R.; Kállay, M. J. Chem. Phys. 2017, 146, 214106. (b) Nagy, P. R.; Samu, G.; Kállay, M. J. Chem. Theory Comput. 2016, 12, 4897-4914. (c) Kállay, M. J. Chem. Phys. 2015, 142, 204105. (d) The MRCC quantum chemical program suite has been developed by Kállay, M.; Rolik, Z.; Csontos, J.; Nagy, P.; Samu, G.; Mester, D.; Ladjánszki, I.; Szegedy, L.; Ladóczki, B.; Petrov, K.; Farkas, M. and Hégely B. See also: Rolik, Z.; Szegedy, L.; Ladjánszki, I.; Ladóczki, B.; Kállay, M. J. Chem. Phys. 2013, 139, 094105.

(29) For the aug-cc-pVTZ and aug-cc-pVQZ basis sets, see: Kendall, R. A.; Dunning Jr., T. H.; Harrison, R. J. J. Chem. Phys. 1992, 96, 6796-6806.

(30) For details of the benchmark analysis, see Supporting Information.

(31) (a) Seebach, D.; Groselj, U.; Badine, D. M.; Schweizer, W. D.; Beck, A. K. Helv. Chim. Acta 2oo8, 91, 1999-2034. (b) Groselj, U.; Seebach, D.; Badine, D. M.; Schweizer, W. D.; Beck, A. K.; Krossing, I.; Klose, P.; Hayashi, Y.; Uchimaru, T. Helv. Chim. Acta 2009, 92, 1225-1259.

(32) (a) Schmid, M. B.; Zeitler, K.; Gschwind, R. M. J. Am. Chem. Soc. 2o11, 133, 7065-7074. (b) Schmid, M. B.; Zeitler, K.; Gschwind, R. M. Chem. Sci. 2011, 2, 1793-1803.

(33) Dinér, P.; Kjærsgaard, A.; Lie, M. A.; Jørgensen, K. A. Chem. Eur. J. 2008, 14, 122-127.

(34) The importance of performing conformational analysis for intermediates and transition states along the reaction pathways was stressed by Gschwind et al. (see ref. 32b). For a detailed conformational analysis of enamine en, see Supporting Information.

(35) The predicted $\Delta G$ deviates slightly from that reported in our previous work ( $\Delta G=-1.6 \mathrm{kcal} / \mathrm{mol}$; see ref. 5$)$, because our present computational analysis revealed a more stable form for the catalyst molecule (for details, see Supporting Information).

(36) The number of TS conformers found within a $2 \mathrm{kcal} / \mathrm{mol}$ free energy window on the four $\mathrm{C}-\mathrm{C}$ bond formation pathways ranges between 2-6 (for a detailed analysis, see Supporting Information).

(37) The preference of transition states with the $\mathrm{NO}_{2}$ groups close to the pyrrolidine ring is due to attractive electrostatic interactions between these groups (for a related analysis, see Supporting Information).

(38) For a detailed comparison of transition states and their relative stabilities, see Supporting Information.

(39) In previous studies (refs. 14 and 15), the DFT calculation were carried out at $\mathrm{B}_{3} \mathrm{LYP} / 6-31 \mathrm{G}^{*}$ level, and the relative energies of transition states were estimated from gas-phase electronic energies. For a detailed discussion on the origin of discrepancies, see the Supporting information. For the limitations of the B 3 LYP functional, see: Kruse, H.; Goerigk, L.; Grimme, S. J. Org. Chem. 2012, 77, 10824-10834.

(40) The most stable transition states reported in refs. 14 and 15 were reoptimized at the $\omega \mathrm{B} 97 \mathrm{X}-\mathrm{D} / 6311 \mathrm{G}(\mathrm{d}, \mathrm{p})$ level and we used the same protocol as described in the Computational
Details to get solution-phase Gibbs free energies for these structures.

(41) Note that applying the present computational method to transition states reported by Gan gives an opposite sense of enantioselectivity.

(42) The optimized structures of the most stable OO and CB stereoisomers are provided in the Supporting Information along with the IRC pathways that confirm the concerted mechanism of $\mathrm{OO} \leftrightarrow \mathrm{CB}$ interconversions.

(43) The profile obtained for the $(S, S)$ pathway is reported in the Supporting Information. Results of IRC calculations for all four $\mathrm{C}-\mathrm{C}$ bond formation pathways are also provided in the Supporting Information.

(44) In principle, other isomeric structures of the $\mathrm{OO}$ and $\mathrm{CB}$ species can be generated in the $\mathbf{e n}+\mathbf{2}$ addition reaction, which differ in the absolute configuration of the ring $\mathrm{sp}^{3}$ carbon atoms that are not involved in $\mathrm{C}-\mathrm{C}$ bond formation. A short discussion on these isomers is presented in the Supporting Information.

(45) In our previous kinetic study of the $\mathbf{1}+\mathbf{2}$ reaction, the OO $^{R S}$ species could be detected in considerable concentration (with $\left[\mathbf{C B}^{R S}\right]:\left[\mathbf{O O}^{R S}\right] \approx 6$ ) pointing to a smaller free energy difference than computed herein. Our benchmark calculations also indicate that the relative stability of the $\mathrm{CB}$ species is overestimated by about $3 \mathrm{kcal} / \mathrm{mol}$ (see Supporting Information).

(46) Alternative protonation pathways, i.e. the protonation of the N-oxide group of $\mathbf{O O}^{R S}$ and the protonation of the $\mathbf{C B}^{R S}$ intermediate were found to be far less favored in our previous work (see the SI material of ref 5 ).

(47) These data refer to free energy differences between $\mathbf{T S}_{\mathbf{C C}}$ and $\mathbf{e n}+\mathbf{2}$ states in the absence and in the presence of pnp. For details, see Supporting Information.

(48) Reactions between enamines and nitroalkenes are rapid processes even in the absence of acid co-catalysts, however, the accelerating effect of pnp could be clearly demonstrated for reactants with bulky substituents (see ref. 4a).

(49) The cat $\cdots$ pnp complex is $2.4 \mathrm{kcal} / \mathrm{mol}$ more stable than the separated molecules. For details, see Supporting Information.

(50) We note that the absolute values of the barriers represented by the $\mathbf{T S}_{\mathrm{CC}}{ }^{R S}$ and $\mathbf{T S}_{\mathrm{CC}}{ }^{S R}$ versus the $\mathbf{T S}_{\mathrm{CC}}{ }^{R S} \cdots$ pnp and TS $_{\mathrm{CC}}{ }^{S R} \cdots$ pnp C-C bond formation transition states should be compared with caution as the two reactions (without and with pnp) differ in molecularity (bi- versus termolecular reactions). The uncertainty of entropic contributions is of particular concern in such comparison.

(51) For details, see Supporting Information.

(52) For a detailed description of the $\mathbf{O O}^{R S} \rightarrow \mathbf{C B}^{R S}$ transformation, see Supporting Information.

(53) For additional transition structures, see Supporting Information.

(54) Note that on pathway $(R, S)$ the $\mathbf{C B}^{R S}+\mathbf{p n p}$ state is only $0.5 \mathrm{kcal} / \mathrm{mol}$ less stable than the $\mathbf{O O}^{R S}$...pnp complex.

(55) The reversibility of the conjugate addition step could actually be demonstrated via crossover experiments using electronically or sterically destabilized CB species (derived from propanal and $p$-OMe- $\beta$-nitrostyrene or isobutyraldehyde and $\beta$ nitrostyrene; see ref. 3a). These reactions were carried out in the absence of acid, so the barrier of protonation is expected to be higher than that of the backward process to the enamine + nitroalkene state enabling the crossover between different cyclobutane species.

(56) For an example, where the selectivity and the reaction rate are controlled by different steps, see: Schmidt,S.; Baráth, E.; Larcher, C.; Rosendahl, T.; Hofmann, P. Organometallics 2015 , 34, 841-847. 
(57) For successful applications of tripeptide catalysts in conjugate additions, see: (a) Wiesner, M.; Revell, J. D.; Wennemers, H. Angew. Chem. Int. Ed. 2oo8, 47, 1871-1874. (b) Wiesner, M.; Revell, J. D.; Tonazzi, S.; Wennemers, H. J. Am. Chem. Soc. 2008, 130, 5610-5611. (c) Duschmalé, J.; Wennemers, H. Chem. Eur. J. 2012, 18, 1111-1120. (d) Kastl, R.; Wennemers, H. Angew. Chem. Int. Ed. 2013, 52, 7228-7232.

(58) We performed DFT calculations for the reaction between 3-phenylpropanal and $\beta$-nitrostyrene examined in back reaction screening experiments and obtained a similar free energy diagram displaying the same qualitative features as those of the $\mathbf{1}$ +2 reaction. For details, see Supporting Information.

(59) COPASI, version 4.16. Hoops, S.; Sahle, S.; Gauges, R.; Lee, C.; Pahle, J.; Simus, N.; Singhal, M.; Xu, L.; Mendes, P.; Kummer, U. Bioinformatics 2006, 22, 3067-3074.

(6o) For detailed description of kinetic simulations and results, see Supporting Information.

(61) The increased barrier of the $C-C$ cleavage step on the major pathway appears to be a general kinetic feature to obtain reversed enantioselectivity in simulations for the back reaction. For details, see Supporting Information.

(62) The reaction time of the preparative Michael addition is not specified in ref. 10a, so we assumed that at the applied conditions the forward reaction reaches $90 \%$ conversion within 3 hours. This estimation is based on a previous work by Seebach et al (see ref. 4a).

(63) For details, see Supporting Information.

(64) Using the rate equations of the present two-step kinetic model with the initial conditions applied in the back reaction screening experiments, the expression obtained for the initial ratio of mass-labeled enamines in the back reaction (i.e. at $\mathrm{t}=\mathrm{o}$ ) is $e r_{0}=e^{\left(\Delta G_{-1}^{\ddagger},-\Delta G_{-1}^{\ddagger}+\Delta G_{-21}^{\ddagger}-\Delta G_{-2}^{\ddagger}\right) / R T}$, where $\Delta G_{\mathrm{i}}^{\ddagger}$ denote the four barriers of the back reaction (see also Figure 10).

(65) For related analysis of rate equations, see Supporting Information.

(66) For preparation methods, see Supporting Information.

(67) Both forward and backward reactions require mixing (stirring or shaking) of the DMSO solution to start and proceed. The presence of water can also affect the measured ratios.

(68) The erosion of enantioselectivity in the back reaction takes place at a very low rate. For related kinetic analysis, see Supporting Information. 

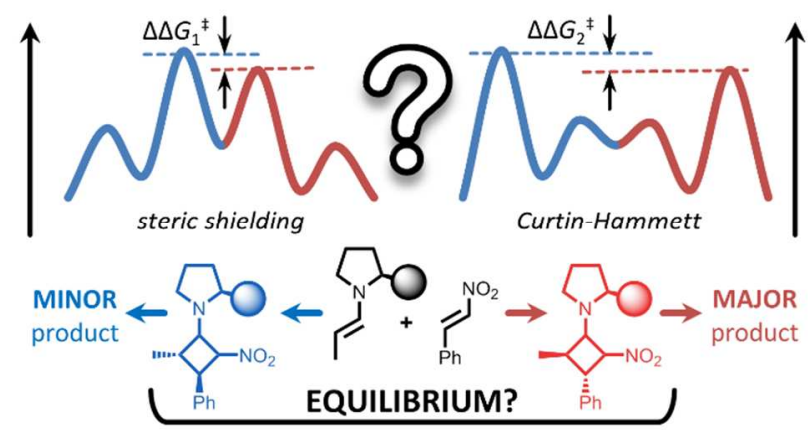

16 